\title{
LITERASI MEDIA DIGITAL GENERASI Z (STUDI KASUS PADA REMAJA SOCIAL NETWORKING ADDICTION DI JAKARTA)
}

\author{
Riyodina G. Pratikto ${ }^{1}$ \\ Shinta Kristanty ${ }^{2}$ \\ Fakultas Ilmu Komunikasi, Universitas Budi Luhur, Jakarta \\ dinapratikto@yahoo.com \\ shintasoultan@yahoo.com
}

\begin{abstract}
Generation $\mathrm{Z}$ is a generation that is active in the use of the internet, they accept social media as something that is taken for granted, with the characteristics of this generation of $\mathrm{Z}$, this generation will be a generation that plays an important role in the development of the State of Indonesia. The problem is that the $\mathrm{Z}$ generation of social media users is dominated by teenagers, the negative impact of excessive use of social media by teenagers can lead to addictive behavior which is referred to as social networking addiction. This behavior is caused by various things, from the lack of parental supervision to the lack of digital media literacy in adolescents, as well as to adolescents in Jakarta, especially in the Pesanggerah region, South Jakarta. Based on these problems, the purpose of this study was to find out how digital media literacy in using social media by teenagers in Jakarta belongs to social networking addiction at the level of technical skills, crtitical understanding and communicative abbilities. This study uses concepts related to media literacy, digital media literacy, characteristics of social media, social networking addiction and Generation Z. The research method used is case-1 case study, qualitative approach, data obtained by in-depth interviews and participant observation, as well as data Secondary sources are related documents, books and mass media. The results of this study were the informants were in a state of digital media literacy that was not optimal, at the technical skill level the informants were able to use social networking, but did not understand the negative impact if using it was too active. At the critical understanding level, the informants did not understand the function, how to sort the contents, and the application of the ITE Law, at the level of communicative abbilities the informants did not select their followers, so they often received negative content or negative comments.
\end{abstract}

Keywords: Literacy, Digital Media, Generation Z, Social, Networking, Addiction

\begin{abstract}
ABSTRAK
Generasi Z merupakan generasi yang aktif dalam penggunaan internet, mereka menerima media sosial sebagai sesuatu yang taken for granted (sesuatu yang
\end{abstract}


sudah biasa), dengan karakteristik generasi $\mathrm{Z}$ ini, maka generasi ini akan menjadi generasi yang memegang peranan penting dalam perkembangan Negara Indonesia. Persoalannya generasi $\mathrm{Z}$ pengguna media sosial didominasi oleh remaja, dampak negatif dari penggunaan media sosial yang berlebihan oleh remaja dapat mengakibatkan perilaku kecanduan yang disebut sebagai social networking addiction. Perilaku ini disebabkan berbagai hal, dari mulai kurangnya pengawasan orang tua sampai pada minimnya literasi media digital pada remaja, begitu pula pada remaja di jakarta khususnya di wilayah Pesanggerahan, Jakarta Selatan. Berdasarkan permasalahan tersebut maka tujuan penelitian ini adalah untuk mengetahui bagaimana literasi media digital dalam menggunakan media sosial oleh remaja di Jakarta yang tergolong social networking addiction pada level technical skill, crtitical understanding dan communicative abbilities. Penelitian ini menggunakan konsep yang terkait dengan literasi media, literasi media digital, karakteristik media sosial, social networking addiction dan Generasi Z. Metode penelitian yang digunakan adalah studi kasus tipe - 1, pendekatan kualitatif, data diperoleh dengan wawancara mendalam dan observasi partisipan, serta data sekunder bersumber dari dokumen terkait, buku, dan media massa. Hasil penelitian ini adalah para informan berada pada kondisi literasi media digital yang belum maksimal, pada tingkat technical skill para informan mampu menggunakan social networking, tetapi tidak memahami dampak negatif jika menggunakannya terlalu aktif. Pada level critical understanding para informan belum paham fungsi, cara memilah isi, serta penerapan UU ITE, pada level communicative abbilities para informan tidak menyeleksi followers mereka, sehingga sering mendapat kiriman isi negatif atau komentar negatif.

Kata Kunci: Literasi, Media Digital, Generasi Z, Social, Networking, Addiction

\section{PENDAHULUAN}

Peneliti tertarik melakukan penelitian mengenai Generasi Z, karena Generasi $\mathrm{Z}$ atau pascamillenial ini adalah kelompok muda yang lahir dari rentang tahun 1996 hingga 2010, mereka dikenal dengan native digital atau generasi net. Sebagai digital natives (generasi yang lahir pada saat era digital sudah berlangsung dan berkembang pesat), mereka menerima media sosial sebagai sesuatu yang taken for granted (sesuatu yang sudah biasa). Ini berbeda dengan generasi orang tua mereka yang masuk dalam kategori digital immigrant (generasi yang lahir sebelum generasi digital belum begitu berkembang). Generasi yang hidup pada era ini memiliki kecenderungan selalu melibatkan media baru dalam setiap kegiatan di kehidupan mereka. Bahkan bisa dikatakan, generasi ini tidak dapat dipisahkan dengan media baru.

Tirto.id melakukan riset kepada 1.201 responden selama lima minggu mulai Maret hingga Juni 2017 di Jakarta, Tangerang, Bandung, Yogyakarta, Surabaya, dan Denpasar. Dari hasil riset yang dirilis 
tirto.id, Generasi Z di Indonesia memiliki ciri khas atau karakteristik sebagai berikut; hemat, berpikiran terbuka, suka pada bentuk kampanye yang kekinian, asyik dengan teknologi, sanggup berkompromi, mengkehendaki perubahan sosial. Jumlah generasi ini diperkirakan mencapai $34,05 \%$ dari total penduduk dunia saat ini, dan pada 2050 akan mencapai $40 \%$ dari jumlah penduduk total di dunia. Dengan karakteristik generasi $\mathrm{Z}$ ini, maka generasi $\mathrm{Z}$ akan menjadi generasi yang memegang peranan penting dalam perkembangan Negara Indonesia ini. Menurut tirto,id, saat ini tercatat terdapat 2,5 Miliar orang Generasi $\mathrm{Z}$ di seluruh dunia. (https://tirto.id/tirtovisual-report-masa-depandi-tangan-generasi-z-

ctMM/diakses pada 29/11/2017)

Sementara itu, mengenai Generasi $\mathrm{Z}$ merupakan generasi yang aktif dalam penggunaan internet, juga didukung data dari Nielsen berikut ini:

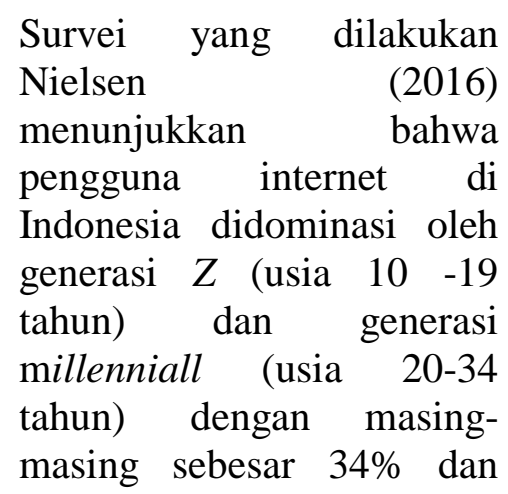

48\%. Ini artinya para pengakses internet baik yang menggunakannya untuk mengakses media daring maupun media sosial kebanyakan adalah pelajar dengan rentang usia 10 sampai 19 tahun.

(http://www.kombinasi.net/l iterasi-media-di-eradigital/diaksespada 29/11/2017)

Permasalahan dalam penelitian ini terfokus pada Generasi $\mathrm{Z}$ yang megalami social networking addiction yaitu remaja, karena berdasarkan data diperoleh bahwa remaja yang mengalami social networking addiction akan bersikap skeptis (mengesampingkan interaksi sosial), berikut ini data nya:

Sebanyak $83 \%$ remaja tidak bisa lepas dari media sosial (medsos) walau hanya sehari. "Fenomena yang sering terjadi pada saat berkumpul, kebayakan hanya terfokus pada gadgetnya masing-masing tanpa memperhatikan apa yang terjadi dan yang sedang diperbincangkan orangorang di sekelilingnya," ujar Siska Kusuma Ningsih Ketua Tim Penelitian, dalam keterangan resminya, Rabu (1/6/2016). Fenomena itu, menurut dia, sungguh memiriskan, tetapi justru banyak terjadi di lingkungan terdekat kita. Artinya, tanpa kita sadari sedikit demi sedikit 'medsos' telah mampu menumbuhkan 
dampak negatif dan berkembang cepat akhirakhir ini. Yang menarik, jawaban atas kuesioner terhadap remaja usia 13-25 di kawasan Kelurahan Mulyorejo Kota Surabaya, dalam intensitas penggunaan medsos selama 24 jam, sebanyak 83\% responden menyatakan tidak bisa lepas dari media sosial miliknya, walau hanya sehari saja. Demikian kesimpulan dari hasil kajian lima mahasiswa Fakultas Keperawatan Universtas Airlangga dari proposal penelitian Program Kreativitas Mahasiswa Penelitian Sosial Humaniora (PKMP Soshum) berjudul Pengenyampingan Interaksi Sosial secara Langsung oleh Masyarakat sebagai Dampak Munculnya Jejaring Sosial (Medsos). Hasil kajian tersebut lolos dan meraih dana hibah dari Dirjen Dikti Kementerian Riset, Teknologi, dan Pendidikan Tinggi (Kemenristek Dikti) tahun 2016.

(http://kabar24.bisnis.com/r ead/20160601/255/553564/8

3-remaja-idap-

ketergantungan-media-

sosialdiakses pada 29/11/2017)

Karakteristik generasi $\mathrm{Z}$ atau pascamillenial yang hidup dengan internet melalui gadget-gadget canggih dapat menghadirkan kecemasan tersendiri, yaitu social networking addiction (bisa diartikan sebagai perilaku kecanduan media sosial), Generasi $\mathrm{Z}$ yang kecanduan media sosial mengalami gangguan pada perilaku, seperti yang dilansir oleh pikiran rakyat .com, berdasarkan pernyataan dr. Miryam A. Sigarlaki, M.Psi. dalam seminar "Problematika Remaja di Era Digital" yang digelar Fakuktas Kedokteran Universitas Jenderal Achmad Yani (Unjani) di Gedung Hindarto Joesman Jalan Terusan Sudirman Kota Cimahi, Minggu, 2 April 2017, yakni perilaku generasi remaja Indonesia saat ini sangat jauh berbeda dengan generasi-generasi sebelumnya. Mereka jadi generasi 'menunduk' karena terpaku pada alat komunikasi gawai canggih, memiliki hubungan lekat di dunia maya namun kebalikan di dunia nyata, selain itu menjadi sinis dan skeptis, kurang sosialisasi, tidak fokus, dan kompetensi sosialnya sangat kurang (http://www.pikiranrakyat.com/bandungraya/2017/04/03/kenali-

karakter-remaja-generasi-z397866/diakses pada 729/12/2017).

Berdasarkan penjelasan tersebut, peneliti menyertakan data mengenai contoh-contoh nyata perilaku negatif remaja yang 
kecanduan menggunakan media sosial Facebook, terlihat pada data berikut:

Citizen6, Jakarta Tak selamanya teknologi canggih membawa manfaat, khususnya bagi para remaja. Sebab tanpa bimbingan yang baik dari orang tua, mereka bisa menghabiskan waktu bermain sosial media di internet.

Yang terparah, mereka bisa kecanduan sosial media. Jika tidak dihentikan, bukan tidak mungkin kecanduan tersebut membahayakan nyawa mereka. Berikut remaja-remaja yang tewas akibat kecanduan sosial media.

\section{Gantung Diri}

Goswami, seorang remaja perempuan dari India, ditemukan tewas gantung diri di kamarnya. Saat ditemukan, matanya melotot dan lidahnya terjulur keluar. Badannnya berputar-putar karena tali yang digunakan untuk gantung diri diikat di kipas angin kamarnya. Orang tuanya mengaku, sebelumnya mereka menegur Goswami karena terlalu sibuk bermain facebook.

Mereka khawatir anak mereka kecanduan dan sering lalai dengan pekerjaan rumah. Toh meski kerap dimarahi, Goswami membandel. Akhirnya suatu kali orang tuanya mengancam akan mengambil ponsel Goswami dan tak dikembalikan. Setelah mendapat ancaman tersebut, ia masuk ke dalam kamar dan menguncinya. Beberapa saat kemudian, ia ditemukan gantung diri di kamarnya.

Dipukul Hingga Tewas

Seorang remaja di Cina bernama Deng Senshan meninggal kurang dari satu hari setelah dibawa ke pusat rehabilitasi internet. Beberapa bagian tubuhnya lebam dan membiru. Disinyalir ia meninggal setelah dipukuli oleh temanteman di tempat rehabilitasi akibat tak mau berhenti bermain sosial media di komputernya. Kecandua internet merupakan masalah besar di Cina. Karenanya, banyak pusat rehabilitasi kecanduan internet yang didirikan di Cina.

Menabrakkan Diri ke Kereta

Tallulah Wilson, remaja perempuan yang juga balerina, memilih bunuh diri karena tak diperbolehkan memainkan ponsel oleh ibunya. Ibu Tallulah menyimpan ponsel dan laptop anaknya karena khawatir dengan anaknya yang terlalu sibuk dengan sosial media.

Saat ponsel dan laptopnya diambil, Tallulah berteriak pada ibunya bahwa di internet ada 18.000 orang yang menyayanginya dibanding di dunia nyata. Diduga ia depresi akibat 
kematian sang nenek dan perceraian orang tuanya. Ia pun memilih keluar rumah dan menabrakkan dirinya ke kereta yang lewat di Stasiun St. Pancras.

\section{Tewas Mengambang di Sungai \\ Jonny Byrne ditemukan tewas mengambang di sebuah sungai setelah lompat dari jembatan saat melakukan neknomination. Neknomination merupakan trend di internet tentang orang yang merekam dirinya di video sambil minum alkohol dalam jumlah yang banyak di tempat berbahaya. Di akhir video orang tersebut mesti meneriakkan nama temannya untuk melakukan aksi yang sama.}

\section{Jatuh dari Jembatan}

Seorang remaja perempuan ditemukan tewas tenggelam di sungai. Di tangannya, ditemukan ponsel yang masih hidup dan menampakkan akun facebook yang ia miliki. Diduga akibat terlalu asyik bermain facebook, ia terjatuh dari atas jembatan ke dalam sungai dan tenggelam akibat tak bisa berenang.

\section{Bunuh Diri Karena Selfie}

Seorang remaja pria di Inggris mencoba bunuh diri karena tidak puas dengan hasil selfie yang diambilnya. Danny Bowman menghabiskan 10 jam dalam sehari untuk selfie sebanyak 200 kali.

Karena merasa kecewa, pemuda ini hampir saja mengalami overdosis, untungnya Ibu pemuda berusia 19 tahun ini berhasil menyelamatkannya. Karena kasus Bowman yang ekstrim ini, para dokter jiwa mulai menganggap jika kecanduan selfie merupakan gangguan jiwa yang tergolong serius.

(citizen6.liputan6.com/read/ 2151238/remaja-remajayang-tewas-akibatkecanduan-sosial-media

Penelitian ini menggunakan perspektif literasi media digital, karena literasi media digital dianggap penting sebagai cara mengatasi remaja yang mengalami sosial networking addiction, yang terjadi salah satunya adalah karena adanya kemudahan dalam mengakses media sosial, dimana dan kapan saja. Diharapkan melalui literasi media digital ini, remaja dapat terhindar dari dampak yang timbul, berupa sikap mengesampingkan interaksi sosial. Kemampuan remaja dalam mengelola penggunaan media sosial sangat kurang, sehingga menimbulkan perilaku kecanduan media sosial, menjadi tidak peduli dengan kehadiran orang lain, tidak memahami situasi dan konteks, serta tidak fokus. Berdasarkan data tersebut, maka peneliti tertarik melakukakn penelitian tentang bagaimana remaja menempatkan dirinya sebagai pengguna media 
sosial (FaceBook, Twitter, InstaGram, dan lain-lain). Untuk itu, peneliti memperoleh data terkait sebagai berikut:

Penyebab remaja mengalami social networking addiction menurut Peg Streep, seorang pemerhati tren digital dan remaja, menuliskan 4 alasan utama remaja menjadi maniak media sosial, seperti dilansir dalam situs Psychology Today, antara lain:

1. Mendapatkan perhatian Hasil penelitian dari Pew Research Center Study, AS, menunjukkan bahwa sebagian besar remaja berbagi informasi di sosial media. Berbagai informasi menjadi kunci bagi mereka untuk mendapatkan perhatian bagi diri mereka sendiri. Mereka seringkali mengeluhkan tentang 'oversharing' yang dilakukan pengguna media sosial ain. Padahal, mereka sendiri juga terjebak di dalamnya. Mereka berbagi begitu banyak hal (bahkan yang bersifat pribadi) di dalam media sosial.

2. Meminta pendapat

Remaja seringkali meminta pendapat dan persetujuan rekanrekannya untuk memutuskan sesuatu. Itu wajar jika di dunia nyata. Namun, dengan adanya media sosial, mereka menjadi meminta pendapat untuk hal yang tidak penting. Contohnya, mereka akan semakin sering menggunggah foto untuk sekadar melihat bagaimana komentar rekan-rekannya. Semakin banyak pujian atau sekadar "Like" di Facebook akan membuat mereka merasa populer. Dengan kata lain, media sosial menjadi indikator kepopoleran meraka. Ada 'kepuasan intrinsik' pada remaja jika mereka populer di media sosial. Bukan hanya lewat foto, remaja seringkali menulis status yang berisikan permintaan saran pada rekan-rekan mereka. Dan, lagi-lagi, ini bukanlah hal yang penting untuk dibagi.

3. Menumbuhkan citra

Media sosial tidak akan mampu mendeskripsikan pribadi seorang pengguna secara utuh. Oleh sebab itu, remaja menjadikan media sosial penumbuh citra positif mereka.Remaja akan cenderung memberikan kesan yang baik saat di media sosial. Mereka berharap orang lain melihat mereka seperti apa yang mereka harapkan.

4. Ketidaktahuan dampak penggunaan media sosial berlebihan 


\begin{abstract}
Mereka akan sulit mengalihkan pandang dari situ. Ketidaktahuan akibat penggunaan media sosial dengan frekuensi yang tinggi, membuat mereka semakin 'terjebak' di dalam nya. Mereka 'terjebak' dalam lingkaran drama media sosial. Meskipun mereka terus mengeluh tentang 'drama' dalam media sosial nyatanya mereka jugalah pelaku drama tersebut.

(https://tekno.tempo.co/re ad/491864/4-alasan-

remaja-gemar-mediasosial/diakses pada 29/11/2017)
\end{abstract}

Berdasarkan data berikut ini remaja dikatakan lebih banyak aktif menggunakan media digital karena masa remaja merupakan masa mencari ciri khas atau jati diri sehingga rasa ingin tgahu yang tak terbendung membuat kebanyakan remaja mencari tahu melalui berbagai sumber di antara nya media digital.

Massa remaja adalah masa transisi seseorang dari tahap anak-anak menuju tahap dewasa. Untuk itu, seorang remaja tidak bisa disebut dewasa, pun disebut anakanak. Berdasarkan

keterangan $W H O$, remaja adalah orang yang berada pada rentang usia 10-19 tahun. Pada rentang usia tersebut, remaja biasanya tengah mencari jati diri.Remaja sebagai generasi $\mathrm{Z}$ bisa dengan mudah mengadopsi tren yang ada di dunia, lantaran akses internet yang sangat mudah. Terlebih lagi setelah Facebook dan Twitter, media sosial seperti Instagram dan Snapchat kini kian digandrungi remaja. Eksistensi remaja di dunia maya sendiri juga beragam. Nukman membaginya dalam dua kategori: Creator dan Conversationalist.

Creator adalah orang yang membuat konten tertentu di blog, situs web, atau pun akun

YouTube. Sedangkan, Conv ersationalist adalah orang yang lebih senang menggunakan Facebook, Path, dan Twitter untuk bercakap-cakap. Generasi Z berada di kategori creator, karena saat ini banyak ruang yang bisa digunakan untuk berkreasi, seperti Instagram. Terlebih lagi, faktor teknologi seperti ponsel pintar, bisa memudahkan generasi $\mathrm{Z}$ untuk membuat foto, video dan editing. (https://www.cn nindonesia.com/gayahidup/20160812134839277-150948/membacagenerasi-z-lewat-perilakudi-media-sosial/diaksespada 29/11/2017)

Secara umum literasi media digital adalah kemampuan, pengetahuan, kesadaran, dan keterampilan secara khusus pada khalayak sebagai pembaca di media 
cetak, peselancar di dunia maya, penonton televisi, atau pendengar radio. Media digital yang dimaksud dalam penelitian ini adalah media sosial yang digunakan untuk berinteraksi, terkoneksi dengan internet, termasuk pengunaan smartphone.

Memahami, menganalisis, dan mendekonstruksi pencitraan media. Literasi media ditujukan agar khalayak sebagai konsumen media termasuk anak-anak, remaja dan orang dewasa menjadi sadar atau melek tentang cara media dikonstruksi atau dibuat dan diakses. Literasi media digital atau yang populer dengan medsos, tampaknya sudah sangat mendesak.

Yang paling sederhana adalah mensosialisasikan bahwa media sosial atau internet itu termasuk bagian dari media baru, yang setidaknya memiliki kekuatan, antara lain, pelipat ganda pengetahuan, menghilangkan jarak ruang dan waktu, mobilitas psikologis, pengaruh mendalam (deep impact), mudah melakukan kreasi (creativity), hingga interaksi/ komunikasi pararasional (tidak rasional) bisa terjadi.

Berdasarkan paparan pada latar belakang penelitian, maka rumusan masalah dalam penelitian ini adalah:

1. Bagaimana literasi media digital pada generasi Z (Remaja Social Networking
Addiction di Jakarta) pada level technical skill?

2. Bagaimana literasi media digital pada generasi Z (Remaja Social Networking

Addiction di Jakarta) pada level critical understanding?

3. Bagaimana literasi media digital pada generasi Z (Remaja Social Networking

Addiction di Jakarta) pada level communicative abbilities?

\section{TINJAUAN PUSTAKA \\ Media Baru}

Kehadiran media baru ini pun membawa perubahan pada proses komunikasi yang selama ini ada, baik komunikasi interpersonal, komunikasi kelompok, bahkan komunikasi massa sekalipun. Masyarakat pengguna media baru ini, seolah terhipnotis, tidak lagi atau jarang berbicara secara langsung, semua dilakukan melalui perantaraan media baru.

"We are already experiencing the cultural effects of the digital revolution that is underway."(Cross, 2011 - dalam Nasrullah; 2015).

Berikut terdapat beberapa definisi media sosial yang berasal dari berbagai literatur, penelitian (Fuchs, 2014), sebagai berikut:

1. Mandibergh (2012), media sosial adalah media yang mewadahi kerjasama di antara pengguna yang menghasilkan konten 
(user generated content).

2. Shirky (2008), media sosial dan perangkat lunak sosial merupakan alat untuk meningkatkan

kemampuan pengguna untuk berbagi (to share), bekerja sama (to co-operate) di antara pengguna dan melakukan tindakan secara kolektif yang semuanya berada di luar kerangka institusional maupun organisasi.

3. Boyd (2009)

menjelaskan media

sosial sebagai

kumpulan perangkat lunak yang memungkinkan

individu maupun

komunitas untuk

berkumpul, berbagi,

berkomunikasi, dan dalam kasus tertentu saling berkolaborasi atau bermain. Media sosial memiliki kekuatan pada usergenerated content $(U G C)$ di mana konten dihasilkan oleh pengguna, bukan oleh editor sebagaimana di institusi media massa.

4. Van Dijk (2013), media sosial adalah platform media yang memfokuskan pada eksistensi pengguna yang memfasilitasi mereka dalam beraktivitas maupun

berkolaborasi. Karena itu media sosial dapat dilihat sebagai medium (fasilitator) online yang menguatkan hubungan antarpengguna sekaligus sebagai sebuah ikatan sosial.

5. Meike dan Young (2012) mengartikan kata media sosial sebagai konvergensi antara komunikasi personal dalam arti saling berbagi di antara individu (to be shared one-to-one) dan media publik untuk berbagi kepada siapa saja tanpa ada kekhususan individu. (Dalam Nasrullah, 2015).

Berdasarkan definisi-definisi tentang media sosial yang dikemukakan para ahli tersebut, maka dapat diambil sebuah kesimpulan bahwa pengertian media sosial itu adalah media dengan menggunakan jaringan internet yang memungkinkan para penggunanya dapat saling berinteraksi, berkomunikasi, menjalin kerjasama, atau pun bahkan membentuk kelompok dan ikatan sosial secara virtual.

\section{Media Sosial (Social Media)}

Media Sosial adalah sebuah media untuk bersosialisasi satu sama lain dan dilakukan secara online yang memungkinkan manusia untuk saling berinteraksi tanpa dibatasi 
ruang dan waktu. Dapat dikelompokkan menjadi beberapa bagian besar yaitu :

1. Social Networks, media sosial untuk bersosialisasi dan berinteraksi ( Facebook, myspace, hi5, Linked in, bebo, dll)

2. Discuss, media sosial yang memfasilitasi sekelompok orang untuk melakukan obrolan dan diskusi (google talk, yahoo! M, skype, phorum, dll)

3. Share, media sosial yang memfasilitasi kita untuk saling berbagi file, video, music, dll (youtube, slideshare, feedback, flickr, crowdstorm, dll)

4. Publish, (wordpredss, wikipedia, blog, wikia, digg, dll)

5. Social game, media sosial berupa game yang dapat dilakukan atau dimainkan bersama-sama

(koongregate, doof, pogo, cafe.com, dll)

6. MMO (kartrider, warcraft, neopets, conan, dll)

7. Virtual worlds (habbo, imvu, starday, dll)

8. Livecast (y! Live, blog tv, justin tv, listream tv, livecastr, dll)

9. Livestream (socializr, froendsfreed, socialthings!, dll)
10. Micro blog (twitter, plurk, pownce, twirxr, plazes, tweetpeek, dll)

(https://www.unpas.ac.id/a

pa-itu-social-media/)

\section{Konsep Literasi Media dan Literasi Digital \\ "Definisi literasi media} menggunakan pendekatan trikotomi yang mencakup tiga bidang yaitu literasi media bermakna memiliki akses ke media, memahami media dan menciptakan dan mengekspresikan diri untuk menggunakan media."(Buckingham 2005, Livingstone 2005).

Sedangkan pengertian literasi media menurut European Comission (European Commission, 2009) adalah:

Media literacy may be defined as the ability to access, analyse and evaluate the power of images, sounds and messages which we are now being confronted with on a daily basis and are an important part of our contemporary culture, as well as to communicate competently in media available on a personal basis. Media literacy relates to all media, including television and film, radio and recorded music, print media, the Internet and other new digital communication technologies. "The aim of media literacy is to increase 
awareness of the many forms of media messages encountered in everyday life. It should help citizens to recognise how the media filter their perceptions and beliefs, shape popular culture and influence personal choices. It should empower them with the critical thinking and creative problem-solving skills to make them judicious consumers and producers of content. Media literacy is part of the basic entitlement of every citizen, in every country in the world, to freedom of expression and the right to information and it is instrumental in building and sustaining

democracy.(European

Commission, 2009)

Literasi digital adalah ketertarikan, sikap dan kemampuan individu dalam menggunakan teknologi digital dan alat komunikasi untuk mengakses, mengelola, mengintegrasikan, menganalisis dan mengevaluasi informasi, membangun pengetahuan baru, membuat dan berkomunikasi dengan orang lain agar dapat berpartisipasi secara efektif dalam masyarakat. Media digital termasuk salah satu gadget dalam media baru, dalam buku Komunikasi dan Komodifikasi dijelaskan definisi media baru (Dennis Mc.Quail, 2000) terdapat empat kategori utama yaitu " 1 , media komunikasi interpersonal seperti email, 2. Media permainan interaktif seperti game, 3. Media pencarian informasi seperti mesin pencarian di Net, 4. Media partisipatoris, seperti ruang chat di Net. Dalam penelitian ini yang dimaksud dengan literasi media digital adalah keahlian atau kemampuan seseorang memanfaatkan komputer, Internet, telepon, PDA dan peralatan digital yang lain sebagai alat penunjang komunikasi secara benar dan optimal".

\section{Model Literasi Media Digital}

Pada penelitian ini, yang digunakan untuk menilai tingkat literasi media hanyalah pada tingkat kompetensi individu saja. Tingkat kompetensi individu terdiri dari tiga kategori yaitu:

1. Technical Skills, yaitu kemampuan untuk mengakses dan mengoperasikan media. Technical skills ini mencakup beberapa criteria, yaitu: kemampuan menggunakan komputer dan internet, kemampuan menggunakan media secara aktif, kemampuan menggunakan internet yang tinggi.

2. Critical Understanding, yaitu kemampuan untuk menganalisis dan mengevaluasi konten media secara komprehensif. Kriteria 
critical understanding adalah kemampuan memahami konten dan fungsi media, memiliki pengetahuan tentang media dan regulasi media, perilaku pengguna dalam menggukana media.

3. Communicative

Abilities, merupakan kemampuan untuk bersosialisasi dan berpartisipasi melalui media serta memproduksi konten media. (European Commission. 2009. In study assessment criteria for media literacy levels. cf.http://cc.europa.eu/av policy/media_literacy/i ndex_en.htm./diakses pada1/12/2017)

\section{Profil Generasi Z}

"Forbes Magazine membuat survei tentang generasi $\mathrm{Z}$ di Amerika Utara dan Selatan, di Afrika, di Eropa, di Asia dan di Timur Tengah. 49 ribu diantara nya anak-anak dan remaja ditanya" (Dill,2015). Atas dasar hasil itu dapat dikatakan bahwa generasi $\mathrm{Z}$ adalah generasi global pertama yang nyata. Teknologi tinggi dalam darah mereka, mereka telah tumbuh di lingkungan yang tidak pasti dan kompleks yang menentukan pandangan mereka tentang pekerjaan, pendidikan, belajar dan dunia. "Mereka memiliki harapan yang berbeda di sekolah, atau pun tempat kerja mereka, berpikir cepat, berorientasi karir, generasi profesional yang ambisius, memiliki kemampuan teknis-dan pengetahuan bahasa pada tingkat tinggi. Oleh karena itu, mereka tenaga kerja yang sangat baik. Pengusaha harus mempersiapkan untuk terlibat generasi $\mathrm{Z}$ karena mereka adalah karyawan yang efektif di era digital". (Elmore, 2014).

\section{Ciri - Ciri Social Networking Addiction}

Sebagaimana diungkapkan dalam artikel yang dituis oleh Leslie Walker tentang "What is Social Networking Addition"? yang dimuat di Lifefire.com:

Addiction usually refers to compulsive behavior that leads to negative effects. In most addictions, people feel compelled to do certain activities so often that they become a harmful habit, which then interferes with other important activities such as work or school.

Social networking addiction is a phrase sometimes used to refer to someone spending too much time using Facebook, Twitter and other forms of social media -- so much so that it interferes with other aspects of daily life.There's no official medical recognition of 


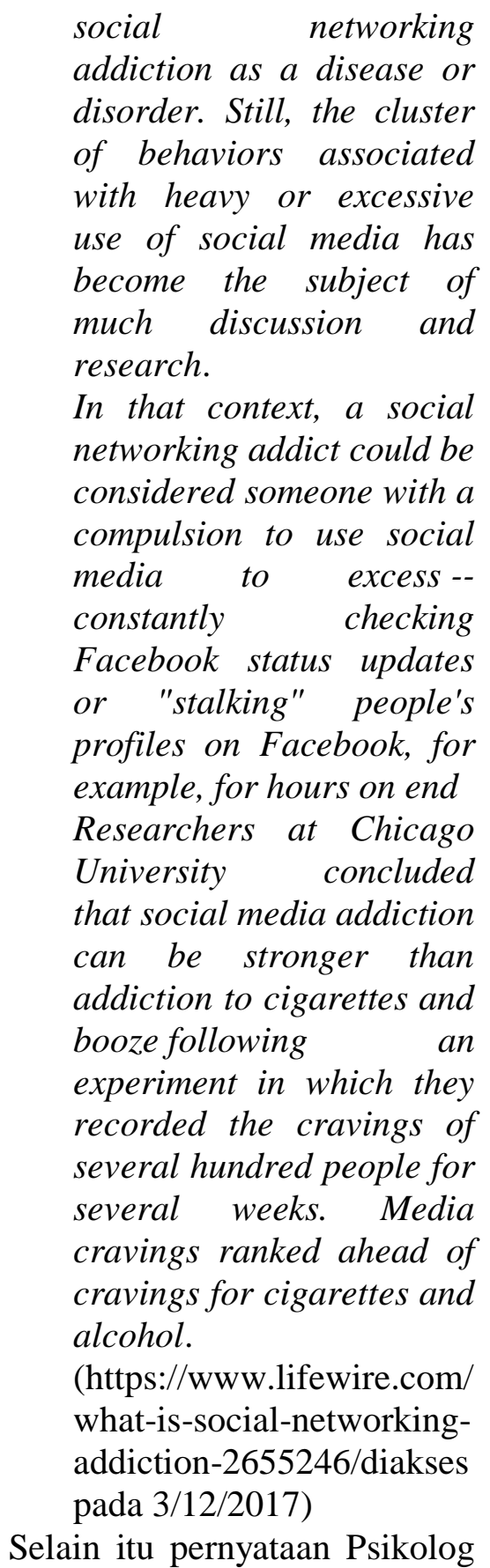

Klinis Anna Surti Ariani M.Psi.

melalui Detik.com dalam rubrik

Detik health menyatakan bahwa, cirri

- cirri perilaku social networking

addiction adalah sebagai berikut:
1. Selalu mengecek news feed di sosial media tiap 5 menit

Ketika kerap mengecek berita terbaru di ranah media sosial demi mengetahui apa yang tengah terjadi dengan teman Anda di dunia maya, bisa jadi Anda tengah kecanduan. Sebab, Anda bisa mengalami kondisi FOMO alias Fear of Missing Out. "Terlalu sering update status, mengubah keterangan dan mengganti foto profil seolah ingin selalu muncul di timeline adalah perilaku yang perlu diwaspadai sebagai gejala kecanduan media sosial," kata dr Suzy.

2. Sering memotret makanan sebelum mengonsumsinya

Baik makan di rumah atau di restoran, kecanduan media sosial membuat Anda ingin memotret makanan tersebut dan mempublikasikannya di media sosial. Bisa dengan tujuan untuk menunjukkan

keeksisan, sekadar sharing, atau bahkan pamer."Perilaku pamer foto makanan di Instagram adalaha hal yang biasa-biasa 
saja, wajar. Perilaku

itu baru dianggap

kelainan jika

seseorang tidak

melakukannya maka

ia langsung pusing

atau merasa ada

sesuatu yang kurang,"

tutur psikolog klinis

Anna Surti Ariani

M.Psi.

\section{Cemas luar biasa saat ponsel tertinggal di rumah}

Bagaimana perasaan Anda jika ponsel tertinggal di rumah? Jika merasa sangat cemas bahkan panik, bukan karena khawatir ada telepon atau pesan penting, tetapi khawatir tertinggal informasi di media sosial, bisa jadi Anda mengalami FOMO yang dikombinasikan dengan nomophobia. Profesor di Indiana University menemukan bahwa $89 \%$ mahasiswa di ruang kerjanya sering merasakan ada getaran di kantongnya seakan getaran ponsel, padahal saat itu ponsel mereka sama sekali tidak bergetar.Kondisi ini sering berkaitan dengan kecemasan ketika menerima SMS, pesan singkat, email, atau update media sosial dari orang lain.

Disarankan, matikan fungsi getar pada ponsel dan berkomitmenlah untuk mengecek ponsel di waktu-waktu tertentu.

\section{Bersaing update info} dengan teman

Salah satu tanda kecanduan media sosial yang kerap tak disadari yakni merasa harus menyamai teman Anda di media sosial yang sering memposting sesuatu. Misalnya seberapa sering mereka check ini di suatu tempat atau seberapa banyak foto selfie yang mereka ambil.

\section{Menarik diri dari} pergaulan sosial

Jika Anda lebih memilih untuk asyik sendiri dengan gadget agar bisa mendapat informasi atau update status dari teman lainnya ketimbang bergaul secara nyata dengan teman Anda, kemungkinan Anda mulai keranjingan media sosial "Orang yang kecanduan media sosial meski tetap bersosialisasi lewat internet tetapi kalau tidak bergaul di dunia nyata maka hal itu tidak bisa dibilang sehat," kata dr Suzy. 
(https://health.detik.co

$\mathrm{m} / \mathrm{read} / 2017 / 09 / 25 / 14$

0204/2701048/763/6/

mulai-kecanduan-

media-sosial-atau-

tidak-kenali-5-ciri-

cirinya/diakses

pada 3/12/2017))

\section{Media Sosial dan Perilaku Remaja}

Penelitian ini sendiri dilakukan oleh tim yang berasal dari University of North Carolinadan $\mathrm{NC}$ State Universitydan dilakukan di Chapel Hill. Sebanyak 487 remaja dilibatkan dalam penelitian yang dilakukan sepanjang satu tahun. Dalam penelitian ini sendiri, para remaja ini dipelajari cara berkomunikasinya

dengan pasangannya baik itu dengan cara tradisional layaknya berkomunikasi secara langsung atau setidaknya bertelepon, dan juga saat mereka memakai media sosial atau aplikasi chat yang kini sedang populer. Selain itu, dipelajari pula cara bersosialisasi dan menjalani hubungan dengan sehat, khususnya dalam mengelola konflik atau mengeluarkan pendapat pribadi atau menyatakan kebutuhan pada orang lain. Pakar kesehatan Jacqueline Nesi dan Mitch Prinstein mengungkapkan jika penggunaan media sosial secara masif berimbas buruk pada cara bersosialisasi remaja modern mengingat media ini tidak mengeluarkan ekspresi wajah saat berkomunikasi dengan orang lain. Bahkan, penelitian ini menunjukkan jika penggunaan media sosial berimbas langsung pada menurunnya ketrampilan berkomunikasi sehingga perbedaan cara pandang, menghentikan argumen, atau sekadar menyatakan pendapat menjadi hal yang bisa memicu masalah yang besar saat dilakukan secara langsung. (http://doktersehat.com/p akar-remaja-kecanduanmedia-sosial-semakinsulit-bersosialiasidengan-baik-di-dunianyata/\#ixzz50nL0iMMq/ diakses pada 4/12/2017)

\section{METODE PENELITIAN}

Penelitian ini dilakukan dengan mengacu kepada payung paradigma konstruktivisme. Paradigma konstruktivisme hampir merupakan antitesis terhadap paham yang menempatkan pentingnya pengamatan dan objektivitas dalam menemukan suatu realitas atas ilmu pengetahuan. Secara tegas paham ini menyatakan bahwa "positivism dan 
post-positivisme keliru dalam mengungkap realitas dunia, dan harus ditinggalkan dan digantikan oleh paham yang bersifat konstruktif”. (Agus Salim, 2006).

Pendekatan yang digunakan dalam penelitian ini yakni pendekatan kualitatif. Terkait dengan metode kualitatif, Pawito mengatakan sebagai berikut: "Metode penelitian kualitatif tidak seperti penelitian kuantitatif, tidak mendasarkan bukti-bukti empirik pada logika matematik, prinsipprinsip bilangan, atau pun teknik analisis statistik, tetapi lebih mendasarkan diri pada hal-hal yang bersifat diskursif, seperti transkrip dokumen, catatan lapangan, hasil wawancara, dokumen-dokumen tertulis, dan data nondiskursif'.(Pawito, 2007). Berdasarkan tujuan penelitian, penelitian ini menggunakan metode studi kasus. Menurut Robert K. Yin (2004): "Studi kasus merupakan strategi yang lebih cocok bila pokok pertanyaan suatu penelitian berkaitan dengan how atau why, bila peneliti hanya memiliki sedikit peluang untuk mengontrol peristiwa-peristiwa yang akan diselidiki, dan bilamana fokus penelitian terletak pada fenomena kontemporer di dalam konteks kehidupan nyata. Peneliti hanya memiliki peluang kecil atau tidak mempunyai peluang sama sekali untuk melakukan kontrol terhadap peristiwa tersebut."
Karakter umum desain penelitian berperan sebagai latar untuk memikirkan desain yang spesifik bagi studi kasus. Empat tipe desain penelitian studi kasus yaitu:

1. Desain kasus tunggal holistik

2. Desain kasus tunggal terpancang (embeded)

3. Desain multi kasus holistik

4. Desain multi kasus terpancang

Terkait dengan topik permasalahan penelitian ini, maka tipe desain studi kasus yang digunakan dalam penelitian ini adalah Desain kasus tunggal holistik, karena penelitian ini memfokuskan diri atau berusaha menjawab masalah-masalah: 1). Bagaimana literasi media digital pada generasi $\mathrm{Z}$ (Studi Kasus Literasi Media Digital Dalam Penggunaan Media Sosial Oleh Remaja Social Networking Addiction)

\section{Kriteria Penentuan Informan}

Berdasarkan penjelasan tersebut, maka peneliti telah menetapkan informan berjumlah lima orang remaja berlokasi di Pesanggrahan Jakarta Selatan, dilanjutkan dengan menetapkan kriteria informan sebagai berikut:

1. Remaja usia 16 sampai 18 tahun (kriteria usia remaja mengacu pada definisi dari WHO/ World Health Organization/ rentang usia 10- 19 th.) 
2. Ada pada kategori social networking addiction: (1). Selalu mengecek news feed di sosial media tiap 5 menit; (2). Sering memotret makanan sebelum mengonsumsinya; (3). Cemas luar biasa saat ponsel tertinggal di rumah; (4). Bersaing update info dengan teman; (5). Menarik diri dari pergaulan sosial. (Mengacu pada kriteria dari Psikolog Klinis Anna Surti Ariani M.Psi, yang dilansir oleh Detik.com)

Peneliti melakukan wawancara yang mendalam (in depth interview) secara langsung dan melakukan pengamatan pada remaja yang tergolong social networking addiction. Jenis wawancara yang dilakukan secara mendalam dengan pertanyaan-pertanyaan yang bersifat umum, yang memungkinkan informan memberikan jawaban terbuka dari pertanyaan yang diajukan. Hal ini dilakukan terhadap informan dengan wawancara tidak terstruktur (unstructured interviewed). Wawancara tidak terstruktur mirip dengan wawancara informal, yang bertujuan untuk memperoleh bentuk-bentuk tertentu dari semua informan, tetapi susunan kata dan urutannya disesuaikan dengan menggunakan pedoman wawancara berisi garis-garis besar dari permasalahan yang ingin dijawab dalam penelitian. Selain itu, wawancara tidak berstruktur bersifat luwes, susunan pertanyaan dan katakata dalam setiap pertanyaan dapat diubah pada saat wawancara, disesuaikan dengan jenis tipe wawancara ini memungkinkan peneliti mendapatkan lebih banyak temuan unik dan informan membicarakan isu-isu penting yang tidak terjadwal.

Selain itu peneliti juga melakukan obeservasi partisipan dengan cara mengamati para informan ketika menggunakan gadget mereka untuk mengakses media sosial, peneliti akan mencatat berapa kali dalam sehari para informan mengakses media sosial, lalu mengamati apa yang dilakukan dengan media sosial nya, namun dalam pengamatan ini peneliti bukan follower pada media sosial para informan.

\section{HASIL PENELITIAN}

\section{Kondisi Literasi Media Digital}

Berikut ini akan dipaparkan hasil peneleitian mengenai kondisi literasi media digital dari para informan yang merupakan remaja dan Generasi $\mathrm{Z}$ (generasi native media digital), dan termasuk ke dalam kategori social networking addiction. Kondisi literasi media digital yang akan dipaparkan dilihat dari sudut pandang Technical Skills, yaitu kemampuan untuk mengakses dan mengoperasikan media. Pertama Technical skills ini mencakup beberapa kriteria, yaitu: kemampuan menggunakan komputer dan internet, kemampuan menggunakan media secara aktif, 
dan kemampuan menggunakan internet yang tinggi.

Kedua dilihat juga dari sudut pandang Critical Understanding, yaitu kemampuan untuk menganalisis dan mengevaluasi isi media secara komprehensif. Kriteria critical understanding adalah kemampuan memahami isi dan fungsi media, memiliki pengetahuan tentang media dan regulasi media, dan perilaku penggunaan media.

Ketiga dilihat dari sudut pandang Communicative Abilities, merupakan kemampuan untuk bersosialisasi dan berpartisipasi melalui media serta memproduksi isi media.

Berikut paparan hasil penelitian:

\section{Technical Skills}

Para informan mengatakan mereka mampu dalam menggunakan internet seperti dari mulai cara mengakses, sampai menggunakan fitur-fitur yang tersedia di social networking nya. Seperti di FaceBook terdapat profil, news feed, picture, status, chatting, inbox, mutual friends, serta fan page. Untuk InstaGram mereka mampu menggunakan fitur upload picture, editing picture, profil, instastory, boomerang. Sedangkan untuk Twitter, mereka mampu menggunakan fitur-fitur seperti retweet, tweet, reply, mention, like tweet dan sebagainya. Berikut hasil wawancara:

"Saya secara teknis bisa Bu, ya seputar ngoperasiin fitur - fitur yang ada di instagram, twitter, facebook ya seperti update news feed, accept friends, mention, retweet, upload, banyak deh" (informan 1)

"Kalau untuk fitur - fitur itu saya bisa sih $\mathrm{Bu}$, yah mention di tweeter, upload, instastory, boomerang juga saya suka di instagram" (informan 2)

"Bisa nya ya hampir semua Bu kalau urusan teknis di instagram saya biasa pakai upload foto selfie, makanan, aktivitas sehari - hari, terus upload foto pakai boomerang, terus masukin instastory, kalau twitter ya ngetweet, reply, retweet, upload foto - fiti sehari - hari juga, kalau facebook ya upload juga, update news feed, kayak gitu" (informan 3)

"Teknis ya saya hampir bisa seтиa, terus sering juga sih pakai social networking nya, paling sering instgram suka iseng pakai instastory gitu, twitter buat ngetweet sama retweet, sama facebook buat update status gitu"(4)

"Saya paling suka ngetweet, update status fecbook, sama upload instagram, instastory, ya seputar fitur lain ya bisa juga Cuma yang sering saya pakai ya itu" (informan 5)

Para informan juga merupakan pengguna aktif social networking juga memiliki frekuensi penggunaan social networking yang tinggi, mereka bisa mengakses lebih dari 30 menit dalam sehari. Para 
informan antara lain mengakses Instagram, Facebook dan Twitter. Setiap hari nya mereka selalu melakukan aktivitas upload foto, gambar, mengganti statis atau menyebarkan informasi-informasi terbaru. Hal ini diakui para informan menyebabkan mereka tidak nyaman jika tanpa gadget yang di dalamnya terdapat social networking, alasan lain adalah agar terlihat selalu eksis di mata para followers nya.

Berikut kutipan wawancara:

"Kalau sudah asyik pakai social networking sih saya bisa berjam - jam bu, apalagi kalau lagi di kamar, paling minimal ya tiga puluh menit-an" (informan 1)

"Saya biasa pakai social networking itu paling sebentar ada sih lima belas menit, terus tiga puluh menit itu udah lumayan lama, biar eksis aja Bu” (informan 2)

"Tiga puluh menit sih ada ya kalau untuk ngecek news feed sama apa yang terbaru di instagram, sama tweeter, sama facebook juga, kadang sepuluh menit tapi nanti buka lagi" (informan 3)

"Ya setengah jam sampai satu jam, kadang saya juga lima belas menit tapi itu juga buka tutup Bu, ga bisa kalau tanpa gadget" (informan 4)

"Setengah jam ya bisa sampai segitu, kalau pas lagi bisa buka, tapi ya kadang buka terus karena biar eksis, temen - temen tuh tau keberadaan saya, saya update terus" (informan 5)

\section{Critical Understanding}

Terkait

critical

understanding, berdasarkan hasil penelitian para informan kurang memahami fungsi, isi serta regulasi media digital. Mereka meng-upload gambar atau foto yang terkadang menuai berbagai komentar negatif dari para followers-nya. Mereka juga membalas komentar tersebut dengan kata-kata negatif. Hal ini menandakan para generasi $\mathrm{Z}$ tersebut memang belum dapat mengendalikan emosi, karena mereka masih berada di usia remaja. Selain itu mereka tidak memahami fungsi social networking tersebut untuk apa. Sebetulnya ketika memutuskan untuk menggunakan social networking, para pengguna tersebut juga seharusnya sudah siap mengelola isi pesan apapun yang mereka upload sendiri dan sekaligus juga feedback seperti apa yang akan diterima.

Berikut kutipan wawancara:

"Saya suka upload foto kegiatan sehari-hari saya seperti kalau lagi jalan-jalan, atau di sekolah, atau pas di kamar, itu saya suka foto diri sendiri, kalau untuk komentar negatif selalu ada aja, ya suka dibales komen juga sih, jadi keikut emosi" (informan 1)

"Paling sering upload foto makan sama selfie, terus saya link ke instagram, tweeter, sama facebook, bia orang pada liat. Tapi komentar negatif jua ada terus, kan saya ngga pilih - pilih followers" (informan 2) 
"Selfie, terus foto-foto makanan, gambar lucu juga sering upload, kalau komentar negatif pasti ada, kadang marah juga, saya tulis aja kata-kata negatif juga buat mereka" (informan 3)

"Saya ngga ngatur-ngatur konten, ya apa yang saya mau upload ya saya upload aja, ngga mikir harus apa atau apa gitu..., ya kalau komentar negatif ada sih, kadang suka saya balesin juga tapi sambil mikir juga dan agak takut" (informan 4)

"Konten ya paling banyak foto saya pribadi, sama alam, ga suka diatur juga isi nya, karena tergantung suasana hati saya aja mau upload nya apa. Ngga mikir juga kalau bakalan ada komen negatif, tapi ya sering dapet, kadang dibales, kadang ngga, suka bikin emosi juga sih" (informan 5)

Para informan juga belum memahami Undang Undang Informasi dan Transaksi Elektronik yang ada saat ini. Sehingga mereka terkadang juga meng-upload informasi bermuatan hoax yang mereka tidak tahu dari mana sumbernya, tidak memahami dalam hal ini artinya, para informan tidak dapat menyebutkan salah satu pasal, mereka hanya dapat mengenali Undang-Undang Informasi dan Transaksi Elektronik dari singkatannya saja yaitu UU ITE, sedangkan dalam penerapannya sama sekali tidak paham.

Berikut kutipan wawancara:
"UU ITE ya tau singkatannya aja, soalnya pernah denger aja dari internet sama berita di televisi, Cuma ngga tau pasal-pasalnya, kalau di sekolah ya ngga tentu juga dikasih kadang sama guru pengetahuannya tapi ngga detil, sama orang tua nga pernah diobrolin juga sih" (informan 1)

"Kalau UU ITE pernah denger sih Bu, tapi saya ngga pernah baca isinya apa. Kalau guru ya paling mata pelajaran T.I.K suka ceritain tapi abis itu saya lupa lagi, karena ngga sering dibahas juga sih" (informan 2)

"UU ITE pernah denger dari televisi aja, ngga paham apa itu, di sekolah pernah dibahas sekali tapi ngga lengkap, kalau sama orang tua juga ngga dikasih tau juga sih, biasa aja kalau ngobrol paling seputar ada berita ini itu" (informan 3)

"Pernah denger sesekali, tapi ga tau juga sih. Dapet sih pelajaran T.I.K tapi lebih ngebahas teknik menggunakan komputer sama internet aja, kalau dampak, UU itu ngga pernah didiskusiin deh kayaknya" (informan 4)

"Pelajaran di sekolah ya ngga terlalu dapet sih Bu, cuma ya tau UU ITE itu kan tentang kita harus tau ngisi konten medsos itu kayak gimana, ngga tau banyak sih saya, cuma tau nya segitu aja" (informan 5)

Terjadinya begitu banyak pengguna media sosial yang belum paham mengenai UU ITE, karena 
belum adanya sumber yang tepat yang menyampaikan kepada para informan, baik dari pihak sekolah, maupun orang tua. Para remaja umumnya, atau para informan khususnya, selama ini hanya mengetahui UU ITE secara sekilas saja, bisa dari membaca di media online, atau dari sekolah melalui pelajaran TIK atau Teknologi dan Informatika saja.

\section{Communicative Abilities}

Communicative abilities yaitu terkait dengan kemampuan untuk bersosialisasi dan berpartisipasi melalui media serta memproduksi isi pesan pada media. Berdasarkan hasil penelitian para informan mampu bersosialisasi dengan sangat baik, dalam hal ini rata-rata para informan memiliki followers lebih dari seribu orang dari masing-masing social networking.

Berikut kutipan wawancara:

"Followers saya ya lebih Bu dari seribu orang sih $\mathrm{Bu}$, nah tapi ngga seтиa nya saya kenal, ya resiko sih Bu kadang ada yang komen macam - macam" (informan 1)

"Saya followers nya banyak $B u$, seribu lebih lah, memang saya ga seleksi orang sih Bu, ya siapa aja saya jadikan followers nya, ya suka dapet komen negatif kadang dikirim ke saya Bu” (informan 2)

"Banyak sih kalau followers $B u$, ga ngitung juga, tapi yang jelas banyak Bu, ngga pilih - pilih juga sih, kalau dapet kiriman yang negatif ya paling saya block" 9informaan 3)

"Banyak nya berapa ya, kalau dibilang seribu kayak nya lebih sih Bu, ga saling kenal juga, ya lebih banyak yang kenal, kalau ada yang ga beres saya unfollow paling" (informan 4)

"Saya ga sadar bahaya nya juga sih Bu, ga mikir sampe ke sana ya ngga tau juga mungkin, intinya ngga kepikiran lah, ya saya senang saja punya banyak followers" (informan 5)

Kelemahan para informan umumnya, tidak mengenal beberapa anggota followers-nya, karena mereka menerima pertemanan begitu saja. Ini berarti para informan belum memahami dampak-dampak negatif dari pertemananan, meskipun mereka sering kali mendapatkan komentar negatif ketika meng-upload gambar, foto atau informasi lain.

\section{Pembahasan}

Berikut ini pembahasan mengenai bagaimana literasi media digital pada Generasi Z (Studi Kasus Literasi Media Digital Dalam Penggunaan Media Sosial Oleh Remaja Social Networking Addiction), khusus nya dari segi Technical Skill, Critical Understanding, dan Communicative Abilities.

Penelitian ini melibatkan informan yang terdiri dari Generasi $\mathrm{Z}$, yaitu para remaja dengan rentang usia 17 tahun sampai 18 tahun. Dikategorikan sebagai generasi $\mathrm{Z}$ 
karena para informan tidak bisa lepas dari gadget, atau akrab dengan penggunaan teknologi dan masuk kategori social networking addiction. Para informan merasa cemas jika gadget mereka tertinggal di rumah, bahkan minimal hampir setiap lima menit sekali mereka mengecek news feed nya. Kemudian, sebelum makan mereka juga sering upload makanan yang akan mereka konsumsi, selain itu beberapa di antara mereka enggan untuk bersosialisasi langsung dengan orang lain secara tatap muka.

Terkait dengan kondisi literasi media, social networking addiction ini ternyata berdasarkan hasil penelitian disebabkan para informan belum maksimal memahami fungsi, isi pesan media, serta dampak-dampak negatif yang ditimbulkan dari menggunakan social networking. Pada level Technical Skill, para informan sudah dengan mahir mengakses social networking mereka, mereka mampu mengoperasikan setiap fitur dari instagram, facebook dan twitter yang sering mereja pergunakan. Namun pokok persoalan nya terketak pada mereka sangat aktif dalam menggunakan social networking tersebut. Karena tidak bisa sehari saja tanpa social networking. Para informan melakukan ini dengan tujuan agar keberadaan mereka diakui oleh para followers nya. Dapat dipahami bahwa para informan belum berada pada kondisi literasi media digital yang maksimal, karena mereka masih belum memahami dampak dari keaktifan mereka dalam menggunakan social networking tersebut, yang tentunya berdampak pada kehidupan sosial mereka.

$$
\text { Pada level Critical }
$$

Understanding, para informan juga belum berada pada kondisi literasi media digital yang maksimal, karena mereka belum memahami fungsi sesungguhnya social networking dan bagaimana mengelola isi pesan media, serta belum pernah membaca UU ITE. Hal ini dilihat dari para informan meng-upload berita-berita yang berunsur hoax, foto-foto diri mereka, aktivitas sehari-hari mereka yang tanpa pertimbangan di-upload dan ini terkadang menuai komentar negatif dari para follower, selain itu para informan juga menjadi tidak memiliki ruang pribadi. Dampak negatif yang ditimbulkan adalah membahayakan keberadaan para informan, namun hal ini sama sekali tidak/belum mereka pahami.

Pada level Communicative Abilities, para informan mengakui berinteraksi dengan followers yang tidak mereka kenal, mereka juga tidak memahami bahaya menerima pertemanan orang-orang yang tidak mereka kenal sebelumnya. Apalagi aktvitas sehari-hari para informan diupload dengan terbuka, rentan terhadap dampak negatif selain juga adanya berbagai komentar negatif yang mungkin dilayangkan pada mereka. Selain itu para informan pun mungkin saja dapat menjadi 
korban kejahatan cyber crime. Dapat dipahami bahwa pada level ini para informan juga belum berada pada kondisi paham/melek media, belum masuk pada tahap paham literasi media digital secara maksimal. Hal ini semakin dimungkinkan terjadi, tidak lepas dari adanya peran orang tua sebagai anggota keluarga terdekat tidak nampak usahanya dalam mengarahkan anak-anak remaja mereka.

Berdasarkan pembahasan yang telah dikemukakan pada ulasanulasan terdahulu, maka dapatlah dipahami bahwa dari setiap level literasi media digital, para informan masih belum maksimal, kalau boleh dikatakan belum paham bagaimana mengelola media sosial yang mereka miliki, mengenali serta memahami penggunaan social networking. Memang mungkin secara teknis mereka sudah dapat mengoperasikannya, namun dari segi isi pesan media, fungsi, dampak, penerapan UU ITE belum mereka pahami secara menyeluruh.

Sebagai remaja Generasi Z, kondisi para informan yang social networking addiction perlu diatasi dengan pembekalan literasi media digital yang dapat diberikan secara reguler. Peran orang tua terutama sangat diperlukan.

Dari 4 alasan utama remaja menjadi sangat tergantung pada media sosial, seperti dilansir dalam situs Psychology Today:

1. Mendapatkan perhatian.
Hasil penelitian dari Pew Research Center Study, AS, menunjukkan bahwa sebagian besar remaja berbagi informasi di sosial media. Berbagai informasi menjadi kunci bagi mereka untuk mendapatkan perhatian bagi diri mereka sendiri. Mereka seringkali mengeluhkan tentang 'oversharing' yang dilakukan pengguna media sosial ain. Padahal, mereka sendiri juga terjebak di dalamnya. Mereka berbagi begitu banyak hal (bahkan yang bersifat pribadi) di dalam media sosial.

2. Meminta pendapat

Remaja seringkali meminta pendapat dan persetujuan rekanrekannya untuk memutuskan sesuatu. Itu wajar jika di dunia nyata. Namun, dengan adanya media sosial, mereka menjadi meminta pendapat untuk hal yang tidak penting. Contohnya, mereka akan semakin sering menggunggah foto untuk sekadar melihat bagaimana komentar rekan-rekannya. Semakin banyak pujian atau sekadar "Like" di Facebook akan membuat mereka merasa populer. Dengan kata lain, media sosial menjadi indikator 
kepopoleran meraka. Ada 'kepuasan intrinsik' pada remaja jika mereka populer di media sosial. Bukan hanya lewat foto, remaja seringkali menulis status yang berisikan permintaan saran pada rekan-rekan mereka. Dan, lagi-lagi, ini bukanlah hal yang penting untuk dibagi.

3. Menumbuhkan citra

Media sosial tidak akan mampu mendeskripsikan pribadi seorang pengguna secara utuh. Oleh sebab itu, remaja menjadikan media sosial penumbuh citra positif mereka.Remaja akan cenderung memberikan kesan yang baik saat di media sosial. Mereka berharap orang lain melihat mereka seperti apa yang mereka harapkan.

4. Ketidaktahuan dampak penggunaan media sosial berlebihan

Mereka akan sulit mengalihkan pandang dari situ. Ketidaktahuan akibat penggunaan media sosial dengan frekuensi yang tinggi, membuat mereka semakin 'terjebak' di dalam nya. Mereka 'terjebak' dalam lingkaran drama media sosial. Meskipun mereka terus mengeluh tentang 'drama' dalam media sosial nyatanya mereka jugalah pelaku drama tersebut.

(https://tekno.tempo.co/re ad/491864/4-alasanremaja-gemar-mediasosial/diakses pada 29/11/2017)

Para informan berada dalam kondisi social networking addiction, karena faktor ingin mendapat perhatian serta ketidaktahuan dampak penggunaan media sosial berlebihan.

Sedangkan dari kriteria social networking addiction Mengacu pada kriteria dari Psikolog Klinis Anna Surti Ariani M.Psi, yang dilansir oleh detik.com, para informan berada pada: (1). Selalu mengecek news feed di sosial media tiap 5 menit; (2). Sering memotret makanan sebelum mengonsumsinya; (3). Cemas luar biasa saat ponsel tertinggal di rumah; (4). Menarik diri dari pergaulan sosial.

\section{KESIMPULAN}

Pada generasi Z (remaja yang mengalami social networking addiction) di wilayah Pesanggerahan, kondisi literasi media digital nya dapat disimpulkan sebagai berikut:

1. Pada level technical skill belum maksimal maksimal memahami fungsi, isi pesan media, serta dampak-dampak negatif yang ditimbulkan dari menggunakan social networking. 
2. Pada level critical understanding belum maksimal ditandai dengan perilaku para informan, yakni mereka belum memahami fungsi sesungguhnya social networking dan bagaimana mengelola isi pesan media, serta belum pernah membaca UU ITE. Hal ini dilihat dari para informan meng-upload berita-berita yang berunsur hoax, foto-foto diri mereka, aktivitas sehari-hari mereka yang tanpa pertimbangan diupload dan ini terkadang menuai komentar negatif dari para follower, selain itu para informan juga menjadi tidak memiliki ruang pribadi.

3. Pada level communicative abbilities literasi media digital juga belum dapat dikatakan maksimal karena para informan mengakui berinteraksi dengan followers yang tidak mereka kenal, mereka juga tidak memahami bahaya menerima pertemanan orang-orang yang tidak mereka kenal sebelumnya.

\section{DAFTAR PUSTAKA}

Buku

Dill, K. (2015). 7 Things Employers Should Know About The Gen Z Workforce, Forbes Magazin, 11.6. Retrieved March 16, 2016, from

http://www.forbes.com/sites/ka thryndill/2015/11/06/7thingsemployers-shouldknow about-the-gen-zworkforce/print/.

Elmore, T. (2014). How Generation $\mathrm{Z}$ Differs from Generation Y. Retrieved July 01 , 2015 , fromhttp://growingleaders.com /blog/generation-z-differsgeneration-y/.

Livingstone, S. and Bober, M. 2004 Regulating the Internet at Home: Contrasting the Perspective of Children and Parents. Paper presented at Digital Generations conference, Institute of Education, London, July. McQuail, Denis. 2000. Mass Communication Theories. Fourth Edition. London: Sage Publication. Newton, Kenneth \& Jan W. Van Deth.

Nasrullah, Rulli, 2015, Media Sosial: Perspektif Komunikasi, Budaya, dan Sosioteknologi, 
Bandung: $\quad$ Simbiosa

Rekatama Media

Pawito. 2007. Penelitian Komunikasi Kualitatif. Yogyakarta: LkiS

Salim, Agus. 2006. Teori Dan Paradigma Penelitian Nasional. Yogyakarta: Tiara Wacana

Yin, K. Robert. 2004. Studi Kasus Desain Dan Metode. Jakarta: PT. Raja Grafindo Persada.

\section{Internet}

European Commission. 2009. In study assessment criteria for media literacy levels. cf.http://cc.europa.eu/avpolic y/media_literacy/index_en.ht $\mathrm{m}$.

https://tirto.id/tirto-visual-reportmasa-depan-di-tangangenerasi-z-ctMM/diakses pada $29 / 11 / 2017$

http://www.kombinasi.net/literasimedia-di-eradigital/diaksespada 29/11/2017

http://kabar24.bisnis.com/read/20160 601/255/553564/83-remajaidap-ketergantungan-mediasosialdiakses pada 29/11/2017

http://www.pikiranrakyat.com/bandungraya/2017/04/03/kenalikarakter-remaja-generasi-z397866/diakses pada 729/12/2017. citizen6.liputan6.com/read/2151238/r emaja-remaja-yang-tewasakibat-kecanduan-sosialmedia

https://tekno.tempo.co/read/491864/4 -alasan-remaja-gemar-mediasosial/diakses pada 29/11/2017

https://www.cnnindonesia.com/gayahidup/20160812134839-277150948/membaca-generasi-zlewat-perilaku-di-mediasosial/diakses pada 29/11/2017

twitter, plurk, pownce, twirxr, plazes, tweetpeek, dll

https://www.unpas.ac.id/apa-itu-

social-media/

European Commission. 2009. In study assessment criteria for media literacy levels. cf.http://cc.europa.eu/avpolic y/media_literacy/index_en.ht m./diakses pada1/12/2017)

https://www.lifewire.com/what-issocial-networking-addiction2655246/diakses pada 3/12/2017

https://health.detik.com/read/2017/09 /25/140204/2701048/763/6/m ulai-kecanduan-media-sosialatau-tidak-kenali-5-ciricirinya/diakses pada 3/12/2017

http://doktersehat.com/pakar-remajakecanduan-media-sosialsemakin-sulit-bersosialiasidengan-baik-di-dunianyata/\#ixzz50nL0iMMq/diak ses pada 4/12/2017 
